\title{
Governing Territories in Turbulence with Advanced Marketing Frameworks
}

\author{
Roberto Bruni ${ }^{1}$, Annarita Colamatteo ${ }^{1} \&$ Evgenia Nekhoda ${ }^{2}$ \\ ${ }^{1}$ Department of Economics and Law, University of Cassino and Southern Lazio, Cassino, Italy \\ ${ }^{2}$ Department of Strategic Management and Marketing, National Research Tomsk State University, Tomsk, \\ Russian Federation \\ Correspondence: Roberto Bruni - Department of Economics and Law, University of Cassino and Southern Lazio, \\ Cassino, Italy. E-mail: r.bruni@unicas.it
}

Received: November 21, 2020

Accepted: December 18, 2020

Online Published: December 25, 2020

doi:10.5539/ijbm.v16n1p79

URL: https://doi.org/10.5539/ijbm.v16n1p79

\begin{abstract}
The world is living in a period of turbulence in terms of health and environmental emergencies, markets and societies complexity. Providing sustainable wellbeing and quality of life to population is a challenge for governments. Policy makers are searching for useful strategies to satisfying the needs of population, and forecasting problems for the future.

Technology, use of data, international cooperation and networks are change-generating forces that cause effects on markets and societies and modify the design, production, and consumption of products and services. Companies manage the factors that stimulate the change, modifying or adapting their management and marketing approaches. The challenge of managing turbulence of societies and the relationship with internal and external stakeholders appears to be more difficult for governments.

Including literature from sociology, geography, and business and management, a selection of multidisciplinary contributions is presented to explain the role of advanced marketing frameworks appliable by governments to overcome the complexity within territories caused by the change-generating forces.

The paper presents the place marketing 'value co-creation driven' as a useful framework to manage the place value proposition by governments, using specific capabilities and a systemic approach
\end{abstract}

Keywords: Territory; place; government; complexity; marketing; value co-creation

\section{Introduction}

Societies of the world are represented by a multitude of entangled networks (Barad, 2003) and each territory is interested in a multiplicity of internal and external difficulties and influences. Everything is connected and the continued dynamism of social and economic changes involves each country of the world.

The effects of dynamism are in the turbulence of economic companies' relationship, stock exchanges, and consumer markets; for this reason, companies improve their competencies, react to the stimuli generated by the macro environment (Lusch et al. 1989; Kotler, 2009), change their organizations and performance. In particular, companies carefully manage technology, knowledge, and international relationship to be reactive and fast in adapting their organizations and value propositions in order to survive the complex scenarios. These dynamics causes a change of the marketing and management approach in the business industry and in many countries, it generates effects even in territory management.

Some authors interpret the companies' behaviors of managing market complexity; in order to explain the relevance of actors' integration into the turbulence of economy and international relationship, some research streams study the role of value interpretation and generation in complex business contexts. In particular, marketing in companies is interpreted as a set of activities, processes, and decision able to define the company strategy following a value co-creation approach (Ramaswamy et al., 2018, Vargo and Lusch, 2004) and for this reason, strictly involving stakeholders - in particular, customers - in each value definition and interpretation. Some theoretical approaches (Gummesson, 2004; Vargo, Lusch, 2016) identify alternative views on marketing and value interpretation sustaining that each value provider in the world - company, territory, country, town, 
people - has to cooperate, generate international networks and integrate resources to co-create value. This idea permits us to consider the value generation as an activity of a multitude of actors that share the purpose to survive a complex context (Badinelli et al., 2012). The consequence is that the role of management is wider than in the past and it is increasingly focused on internal and external resources integration and networks development. The involvement of actors in value creation (Gummesson et al., 2009) and the role of technology (Mele et al., 2011) stimulate the companies to find new meanings for marketing and management concepts and for the value creation in markets in general.

Positive and negative aspects caused by an unpredictable change in societies and markets involve not only companies but even territories and places. The governments, regardless of their level in the territory, should work day by day to support their places that live under the pressure of actors - internal and external stakeholders which have their personal goals; each territory is interested in investments and activities of a multiplicity of actors and the territory development should come from the contribution of professionals, specialists, and residents (Sansone, 2012). The fast dynamics of social and political development and even the environmental disasters and health emergencies force governments to make the best efforts to perceive and understand what are the forces that stimulate the change at international levels and how it is possible to manage this dynamics and complexity in places.

The territories and places can survive the complexity with updated marketing and management capabilities, because they are organizations to be managed; these competencies could be imported from business and management contexts and this is what has been done for the past thirty years. From the early '90s scholars and practitioners have been interested in place marketing research and practical application, taking experience from business contexts, but the focus has been generally narrowed down to 'the place communication' (Kotler et al., 1993; Van den Berg et al. 1994). Those research streams are in the realm of 'place marketing demand-driven'. Following the evolution of marketing and management in advanced business contexts, the place marketing is getting a new role in government, beyond the simple communication (Anholt, 2008; Govers et al., 2009; Oakes et al., 2011), and place marketing is going to be considered a strategic framework (Bruni et al. 2017).

Including literature from sociology, geography, and business and management research streams, this research selects multidisciplinary contributions to explain the role of advanced marketing frameworks applied by government to overcome the complexity within territories. Considering the world social and economic dynamics and looking at the analogies from the different research streams, specific capabilities and systemic approach seem to be useful to manage the place value proposition.

After a selection of research streams, the research presents the change-generating forces that in this period are conditioning the governments of the world and the comparison between place marketing 'demand-driven' and place marketing 'value co-creation driven'.

\section{Method}

This conceptual paper has the aim to explain that advanced marketing frameworks applied to business and management practices can be applied to territories and places in order to better manage the environmental dynamism and complexity.

Based on a literature selection of works from several disciplines and reports by international institutions, parallelism is identified between human geography and business and management studies. In particular, advanced marketing frameworks could be applied to place management because analogies occur in societies, markets and the complexity of business management. Socio-economic literature creates a bridge between the disciplines describing the place dynamics and business and management literature. This bridge justifies the place marketing value co-creation driven that could be applied by governments.

\section{Literature background}

In order to explain how advanced marketing frameworks are useful to help governments to reduce the perceived complexity emerging by markets and societies, literature contributions follow. At first, contributions about complexity and territories are presented. Further, in order to shed light on market complexity, alternative marketing and management frameworks in business contexts are explained, highlighting the role of value co-creation. The paragraph ends with a brief presentation about the place marketing concept evolution.

Complexity is defined as a property of a system, likely to show behaviors that are not all pre-determinable, even if potentially foreseeable by an intentional observer of this system (Le Moigne, 1985). For this reason, complexity is perceived by the observer that is in contact with the analyzed system. At the same time, territory 
can be considered as a system of assets and interacting actors that is analyzed by the government. That is even confirmed by social constructionism. As for social constructionism (Berger and Luckmann, 1967) people engaged in interactions and social practices can interpret and create a shared social reality building a sense of the social world (Giddens, 1984). Four assumptions explain this approach to society: a) society is built socially, and individuals engaged in interaction and social practices create the reality. The shape of the reality is built by actors' perception of the world. Different actors have different perceptions of the reality and its homogeneity comes only by shared culture and knowledge; b) knowledge changes during the time and depends on the cultural context; c) the actions of the actors are able to influence the knowledge (and the culture) and vice versa. The decision of interaction comes from knowledge and social perception; d) the language (and the shared institutions) is a tool of intermediation between an individual (actor) and society.

The actors' interactions within the different social contexts of the world are affected by turbulence in network interactions (Greenspan, 2007). Governments work in turbulence managing the complexity emerging by actors' interactions generated by a worldwide resource integration (globalized companies and products, fast communication, hyper-connection). No physical boundaries are able to reduce the threats (and the opportunities) coming from the turbulence of interactions. International organisms present reports that show complexity in territories caused by the turbulence of interactions, independently by developed or underdeveloped countries (United Nations Report, 2020). Some authors listed and identified place difficulties from different points of view in particular: corruption, pollution and social disadvantages (Leitão, 2016); partial autocracy or democracy, discrimination and infant mortality (Goldstone et al, 2010); degradation and competition for resources between territories (Zidiat et al., 2017); difficult relationship between people and organizations (Jāhāna, 2016). These conditions generate changes in societies and consumptions. Governments can reduce the effects generated on population by improving the actors' interaction with shared rules and encouraging cooperation.

As asserted by the phenomenologists (Casey, 1997; Malpas, 2008), the human-being is integrated within the place and for this reason, complexity emerges from the different interpretations of the context. Seamon (2013) sustains that the place emerges in any 'environmental locus' when human experiences, meanings, and actions are gathered; for this reason, the concept of place is in resource integration and actors' interaction. Tangible and intangible resources and the users' experiences are able to define the actors' interactions and contribute to attracting and facilitating economic development (Musterd, Murie, 2010). In that context, the role of knowledge assumes relevance in order to generate territory development, technology understanding, abilities in managing relationship between place stakeholders/actors (Polese, 2009), and, of course, it reduces the perceived complexity.

The government has been always characterized by human activity and resource integration. For this reason, the development of countries, cities, and towns comes from environmental evolution and human activity. Specific research streams in geographic literature focus on the relationship between material/tangible and immaterial/intangible elements like hard and soft elements. Cresswell and Hoskins (2008) sustain that the materiality of the place is identified by the territory, the boundaries and the topography; the immateriality is a realm of meaning that comes from the different interpretations of involved and interactive subjects/actors that today are influenced in their perceptions by technology and data interchange (Graham, 1998). In particular, the place is not only the materiality - simply to observe - but it is a set of peculiarities coming from the experiential, cultural, and emotional resources (Pred, 1984). At the same time the materiality of buildings, public spaces, malls, pubs, and stations are relevant to stimulate the reaction and the experiences (immateriality) of people, identifying the concept of 'third place' (Rosenbaum, 2006) where people recognize the comfort as home because perceived as familiar and welcoming (Glover et al., 2009). In these almost informal places, it is possible to share and respect unwritten codes and rules, and follow informal relationship, and it often can be recognized and managed in online social networks.

The relevance of actors' interaction emerges and the role of governments is to manage and improve the relationship between people and territories going beyond the complexity and favoring the emerging of the place.

\subsection{Business management, marketing approach, and value co-creation}

The turbulent markets, societies, and places bring people and organizations to improve their capabilities and to contextualize themselves, making them to study the context change and adapt the organization. The concept of dynamics capabilities (Teece et al., 1994; Teece, 2014) emerges within the business and organizational studies and explains the relevance of capabilities like sensing - to perceive the stimuli coming from the environment; seizing - to find the right dimension of the own offering; and transforming - to reorganize the nature of the 
organizations becoming, if it is necessary, a different value provider. The presented model supports companies to increase opportunities in order to manage the emerging complexity and better regulate the interaction with the context and the network of involved actors.

Especially in the business context, actors interact and cooperate in co-creating value following their specific goals but contributing to creating the conditions in order to survive the systems following the win-win logic (Polese et al. 2017). This is a condition of a network that survives the complexity because each actor involved in the relationship gains its benefits (Håkansson, Snehota, 1995). As the value cannot be realized by a single actor, it is always the result of a multitude of interactions (Gummesson, 2004) and interpretations. The concept of value is strictly connected with the environment and with the emerging context in which actors are integrated. In the context of network and systems studies, the value co-creation concept emerges and assumes a relevant role in business, management, and marketing studies.

The concept of value co-creation has been widely analyzed in literature; two literature reviews present the theoretical perspectives on this relevant topic. The first by Galvagno and Dalli (2014) segments scholars about value co-creation in three perspectives: the first perspective includes works in service science where co-creation is the constitutive and intrinsic element of service; the second perspective is based on researches in innovation and technology - co-creation is in customer-company interaction; the third one collects the marketing and consumer research perspective where the research focus is on the customer's role in the co-creation process. A few years later, the follow-up study by Ranjan and Read (2016) identifies the co-production and the co-creation relating to value-in-use between the major streams of research. The new sensitiveness of companies and the market competition are bringing the companies to have a wider marketing approach. It can be applied to every organization because the new approach is based on sharing information and knowledge and also on the involvement and engagement of internal and external stakeholders in value co-creation marketing strategy.

In terms of business and management, the role of resource integration and value co-creation in place relationship can be supported by the S-D Logic approach (Vargo et al., 2004; 2016). From the companies' perspectives, this research stream supports different understandings around the concept of the immateriality of applied competencies to generate a benefit (the service). The presented framework sustains that in a context made by actors, it is possible to generate a value that is co-created by the interaction of a network of actors that express their efforts sharing and integrating their resources, generating specific benefits for all the parties involved in the process. Within the relationship between organizations and people, the technology and knowledge assume a relevant role (Maglio, Spohrer, 2008a) and its evolution is interesting everyday life of people necessarily conditioning markets and consumptions (Hermann et al. 2016), stimulating the emerging of the relevance of data (Erl et al. 2016; de Camargo Fiorini et al. 2018) and their management in every context. The use of data generated by a large use of internet connection by people around the world is conditioning consumption and production of goods and services; big data is the locution used to express the gorgeous amount of data generated by people, using the internet and social networks (Davenport, 2014; Goes, 2014) but even by companies, integrating their activities with high technology and, of course, by cities, with smart cities projects (Townsend, 2013, Caragliu et al., 2013).

\subsection{Place marketing}

Due to the fact that the marketing concept is strictly connected with the markets and business studies, a link between place studies and business and management is represented by place marketing research streams.

From the early '90s place marketing 'demand-driven' has been studied applying the concept of communication and some basic marketing tools from companies experience to the territories. The first place marketing perspective was based on place promotion (Ave, 1994; Borchert, 1994). When the role of marketing became more strategic for companies, researchers tried to apply the same frameworks to the territories thinking about the strategy and customer/user behavior interpretation (Ashworth et al., 1990; Kotler et al., 1993). In the period of 2000 and 2011 different authors suggested to consider place marketing and place branding as independent research streams sustaining that each research stream has its own relevance and it needs specific theories and adaptation (Anholt, 2008). The last studies on place marketing and place branding consider governments in places and their need to overcome the complexity of the network (Parker, 2008; Sansone, 2012; Bruni, 2014; Ashworth 2016) looking at the necessity to express the place value proposition and the opportunity to realize a sustainable and shared place strategy even based on technology and knowledge improvement that starts with the wellbeing and quality of life improvement for residents (Insch et al., 2008; Florek et al., 2020) and stakeholders (Kotler, 2014). 
Integrating the previously presented views with the service science and network and system theories, the place marketing 'value co-creation driven' (Bruni et al, 2017) grows up and emerges as a mean to identify the strategy for the future of the place. This approach contributes to optimizing (or eventually changing) the place vocation by integrating resources coming from all stakeholders.

\section{Results}

International reports and literature explain that countries are affected by numerous situations causing turbulence in socio-economic contexts. The list represented in Figure 1 is a not-exhaustive set of factors determining the perception of complexity and turbulence for government; there is not a starting factor because each one is an effect and cause for another or it is part of a system of effects and causes. The factors contemporarily interest the government and people living in the place because, like in a customer-company relationship, it is impossible to consider causes and effects generated only by one side and each activity or relationship is integrated. For this reason, negative and positive aspects of change in communities are generated or can be considered the result of internal and external inputs.

Factors contribute to representing a scenario that involves the governments every day and contribute to defining the addresses of internal and external stakeholders' choices. No relevant results are identifiable in analyzing the effects generated by a single factor over the government, because the whole (positive or negative) effect of their interaction comes from the synergistic effect of actors interaction. Not always it is simple to identify solutions able to satisfy each stakeholder and, at different levels organization - country, regions, cities -, the local government should manage resources trying to satisfy internal and external stakeholders, the population included. The factors represented in figure 1 influence the government decisions and generate turbulence in places in terms of socio-economic contexts, especially for medium and long period projects. Of course, the turbulence generates confusion that is perceived as complexity by government and involved stakeholders.

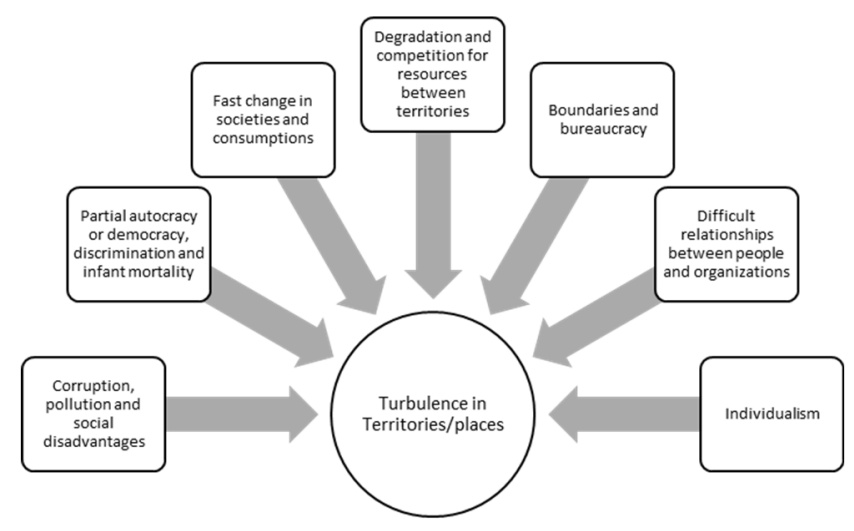

Figure 1. Factors determining the perception of complexity for governments

Source: authors elaboration.

The perceived complexity should be managed by government through relationship management with stakeholders, working on increasing the level of knowledge per each factor and on the impact that the factors have with the whole place strategy. Different priorities in stakeholders relationship management give different interpretations of each factor and the level of turbulence and complexity could be differently perceived. For this reason, if a government is focused on strengthening the relationship and the projects with stakeholders in the industrial production sector, of course, each factor in Figure 1 assumes a specific meaning-affecting the perceived level of turbulence and complexity. At the same time, a government works on involving population in place strategy definition, it will manage limits and opportunities coming from the cited factors differently.

Every factor creates limits in place development and it can be generated, changed, modified, eliminated, or strengthened by the society that every day changes itself (Berger and Luckmann, 1967; Giddens, 1984). At the same time, society creates the 'change generating forces' (Table 1). 
Table 1. Change-generating forces creating dynamism

\author{
Technology \\ Use of data \\ International networks and service exchange \\ Knowledge diffusion
}

Source: authors elaboration.

At the international level, change-generating forces stimulate markets to change fast and the whole economy to be unpredictable. Companies arranged solutions and new frameworks to be effective and to design alternative strategies for the future, identified a new way to communicate and new opportunities to have contacts with customers and entire supply chain where technology has the role of a 'medium' in the turbulent world. They simplified their proposals interpreting the concept of value proposition and identifying frameworks based on actors relationship and resources integration without territorial boundaries. Unlike the past, the hyper-connection and the will to be integrated into a world wide network reinforce the relevance of the change-generating forces that have effects on the places. Companies work exploiting the social change and the role of the 'change generating forces' to stimulate people to cooperate applying competencies to generate benefits (Vargo, Lusch, 2016), to take data and information through direct and indirect communication among consumers, and to increase the effectiveness of their activities connecting the activities coming from the worldwide value networks. The networks are strengthened by fast communication that permits companies the integration and exchange of resources.

The effects obtained by companies and stimulated by technology and data diffusion generate effects on places because they stimulate reactions and experiences for people (Rosenbaum, 2006). Each country, city, or town is interested in a multitude of stimuli and interactions between internal and external stakeholders (Kotler, 2014), so the governments are in the middle of focusing their actions tuning the expectations under direct and indirect pressure coming from a multitude of actors. The value proposition of each country, city or, in general 'territory/place' within the actual social and economic world context is conditioned by the change-generating forces. The system of forces provides continued pressures on places creating and changing material and immaterial elements that represent the system of meanings for each place (Cresswell et al., 2008). Each force produces positive or negative effects in territories/places and influences the place value proposition creating turbulence and perceived complexity. Every effect is generated both from the government's capability to manage the adoption/use/exploitation of change-generating forces on the territory and the openness of territory/place actors to the worldwide activity and social dynamics. A government cannot manage the effects of the change-generating forces only by law, rules or creating constraints - for example, it cannot reduce the adoption of technology or limit the use of data. At the same time, it is impossible to incentivize the adoption of these factors in the territory/place in a short period without specific political activities and infrastructures able to encourage the positive exploitation of the forces from people and companies side. Every result depends on the government's capability to express its place value proposition, involve people and stakeholders in integration of a process that generates the conditions to use the change-generating forces. The technology diffusion, communication and the use of data support governments and development; for instance, smart city systems are being increasingly used to optimise the functionality and efficiency of cities.

For this reason, like the companies and the business industry, the governments need new or alternative frameworks to manage the 'change generating forces' and involve actors in a place for interaction, living there in a sustainable way, and sharing the fundamental concepts of value. The process starts with the context change perception and follows the strategy definition, involving internal and external place stakeholders. Of course, each actor has its own goals but, respecting the place it is possible to contribute to supporting the government to achieve the place final purpose. Actors follow their personal goals in a territory but they can contribute to creating the conditions to obtain the survival of the territory/place (Polese et al., 2017).

The governments can be supported with an open framework able to exploit opportunities coming from change generating forces. This framework should support governments in applying an advanced marketing approach to the place, overcoming the concept of place marketing 'demand-driven' and adopting the place marketing 'value co-creation driven' as an alternative approach to bring together internal and external stakeholders toward a shared final purpose of the place. 


\section{Discussion}

Territories and places could be considered as systems managed by governments that work within the complexity of the socio-economic contexts, entangled in a multitude of actors interactions. The limits (or opportunities) are mainly generated by the way to interpret and manage the change-generating forces (table 1). Actors around the world continuously stimulate the emerging of innovation, create new knowledge, generate data and affect the place development. In order to manage the dynamism and, considering it as an opportunity instead of a threat, government should expand the capabilities and become more flexible and able to perceive the change and the trends in evolution. For this reason, using the business and management literature it is possible to consider that government should develop dynamic capabilities (Teece, 2014) in order to be able to 'sense' the change factors, 'seize' the place value proposition and eventually 'transform' the place strategy for the future. This concept is useful to briefly explain how government should react to the change and how it is necessary to be ready to understand the exact moment to adapt the management and, sometimes, the goals. Government can be supported by business and management frameworks because of the common sociologic and economic roots and, for this reason, it is possible to consider that the business frameworks overcoming complexity can be useful for governments in applying advanced marketing frameworks to improve government performance. The marketing framework is studied within business and management literature and it has been updated considering the complexity and turbulence of the environment. As presented before, concepts as value co-creation, actors' interaction and knowledge diffusion expanded new marketing approaches that could be applied to every organization affected by the environment complexity. New government styles can switch the logic from vertical (bottom-up or top-down) toward horizontal (where, although a government is present, ideas and insights for the future could come from each involved actors). Further, it is possible to consider the role of resource integration and knowledge exchange between the main pillars of organization management by looking at the value proposition definition. To define a value proposition is the main goal of each organization and the recognition of the value provided by the potential users is the final purpose. Government can adopt a new marketing approach to be able to generate the right connection with users/residents, in order to satisfy their needs involving them in cooperation (value co-creation) from the proposal design till the use and adoption in the context of place.

The new marketing approach can be considered a new way to better contextualize governments to turbulent and dynamic environments; every concept and proposal can grow up by the shared interest to cooperation showed by involved actors. Of course, it is necessary to better define the final purpose of the government, which in general should be characterized by achievement of well-being and an improvement in the quality of life of citizens and actors involved.

Following a different interpretation around place marketing it is possible to consider place marketing within a value co-creation logic. The value co-creation concept applied to the places transforms every cooperation within the place into an opportunity to generate value for actors and, at the same time, to support the place to achieve its final purpose. As each actor in place should represent a value offer, there is a role for government to regulate the integration of resources and relationships between actors, supporting the value co-creation, stimulating the generation of mutual benefit and encouraging the sharing of knowledge. Bruni et al. 2017, explains that it is possible to compare the traditional place marketing logic (place marketing demand-driven) and place marketing value co-creation driven (Table 2).

Table 2. Comparing place marketing approaches

\begin{tabular}{|c|c|c|c|}
\hline & Value & $\begin{array}{l}\text { Marketing process managing the } \\
\text { resources }\end{array}$ & Keys for strategy effectiveness \\
\hline $\begin{array}{l}\text { Place marketing } \\
\text { 'demand-driven.' }\end{array}$ & $\begin{array}{l}\text { Value creation generated by } \\
\text { the territory government. }\end{array}$ & $\begin{array}{l}\text { Using available resources to optimize } \\
\text { the place vocation and attracting new } \\
\text { resources to improve or change the } \\
\text { place vocation. }\end{array}$ & $\begin{array}{l}\text { (a) social equilibrium and cohesion, } \\
\text { (b) environmental sustainability and } \\
\text { (c) economic competitiveness. }\end{array}$ \\
\hline $\begin{array}{l}\text { Place marketing value } \\
\text { co-creation driven }\end{array}$ & $\begin{array}{l}\text { The value determined by the } \\
\text { beneficiary (co-creation). The } \\
\text { governing body of the territory } \\
\text { is one of the actors able to } \\
\text { provide a value proposition. }\end{array}$ & $\begin{array}{l}\text { Optimize or change the place vocation } \\
\text { by integrating resources of all place } \\
\text { stakeholders, applying competencies to } \\
\text { generate benefits. }\end{array}$ & $\begin{array}{lll}\text { (a) Value co-creation } & \text { (b) } \\
\text { Environmental sustainability } & \text { (c) } \\
\text { strategic benefits to place and users. }\end{array}$ \\
\hline
\end{tabular}

Source: Bruni et al. (2017).

As presented in table 2, the first perspective, place marketing 'demand-driven', considers the place marketing as 
a useful framework for organizing a place value proposition to be addressed toward the specific place demand that is not always directly involved in value creation (this is mostly a vertical approach). The second approach is focused on value co-created by the multitude of actors involved. For this reason, each actor should be able to contribute to generating value and, at the same time, should be able to provide a value proposition stimulating the resource integration between actors. It is not only the government that should be the value provider for the place, and this reason, each actor can contribute to optimization (or change) the place vocation applying their competencies to obtain benefits (Vargo, Lusch, 2004) (this is mainly a horizontal approach).

In a world characterized by a system of interactions, with an economy and social life influenced by fast communication and a network of relationships, where actors are searching for their individual opportunities, law and rules are not enough to limit the territories exploitation. For this reason, it is necessary to change the government approach. By the place marketing value co-creation driven, it is possible to define a strategy to improve the well-being and quality of life of residents and to attract investors working on medium and long-term goals. The following table 3 may be helpful in explaining the meaning of the suggested marketing framework and in explaining practical applications, highlighted needs and limits.

Table 3. Marketing value co-creation driven: meanings and application

The value determined by the beneficiary (co-creation)

Looking at the principle of co-creation, the governing body of the territory is only one of the actors able to provide a value proposition and each actor contributes to the recognition and creation of shared value. For this reason, the role of the government passes from the leadership position to a more meta-managerial role, of course, addressing the main strategy of the place but encouraging each actor involved to suggest and implement ideas and projects to be developed with the maximum number of internal or external stakeholders in the place.

Value

Application needs and limitations

- $\quad$ Shift in the decision making. Ideas and projects should be shared and co-designed with the actors involved;

- Government should accept the need to spend time regulating actors' relationships till the end of the mediation process

- Actors should share the same institutions (languages used, codes, rules, approaches to problems to give everyone the opportunity to contribute)

- Some processes may be time-consuming

- Government should work as meta-manager to encourage the value co-creation

Optimize or change the place vocation by integrating resources of all place stakeholders, applying competencies to generate benefits.

The place marketing framework can work on the place vocation, based on the situation that the place lives in. For example, an industrial city can expand or optimize its own positioning by involving internal actors to work together to enhance investments and activities in the industrial sector creating new opportunities for stakeholders. On the contrary, it is possible to change the place vocation by creating a new strategy for the future, looking at new assets and new actors with the right knowledge, which is able to create opportunities and strategic benefit for the place. This is, for example, a situation where a place would like to shift the focus from agriculture to service industry or tourism,

Marketing encouraging companies to invest in a new project for place development. Internal and external stakeholders should process managing the resources identify a place where they can express their ideas and apply their competencies, knowledge and, of course, investments with the aim of involving other actors in creating or optimizing a place vocation. The place vocation should be the result of the effort and satisfaction of each actor involved.

\section{Application needs and limitations}

- $\quad$ Effective place analysis to be shared

- $\quad$ Sharing knowledge and data about the place and stakeholders involved

- Creating opportunities for discussion and meetings with people and organizations including residents

- Internal and external stakeholders have the same rights in sharing ideas and projects

- Be open to 'good ideas' coming from parties and actors not directly related to government

- $\quad$ Respect for the final purpose of a place (well-being and quality of life for people) is a unique constraint

Environmental sustainability

Keys for strategy When considering place management, of course the concept of sustainability is at the centre of every strategy for the effectiveness future, but in this marketing approach, the concept goes beyond the environmental interpretation, explains that the strategy is tied to the actors' integration and the final purpose of the place marketing value co-creation approach. Sustainable thinking is primarily a way to achieve the final purpose of a place based on creating well-being and a 
better quality of life for people involved. The concept represents one of the shared institutions able to stimulate actors to develop projects design based on medium and long-term effects, integrated with other projects, avoiding conflicts and generating benefits for the whole place-system, and not only for the actors directly involved. In addition, the generated effects should have little impact on the environment and the way to the final purpose of a place.

Application needs and limitations

- Sustainability recognized as an institution

- To adopt the medium and long-term approach

- The actors' goals should be consistent with the final purpose of the place marketing activity

- $\quad$ Every action must have a low impact on the environment

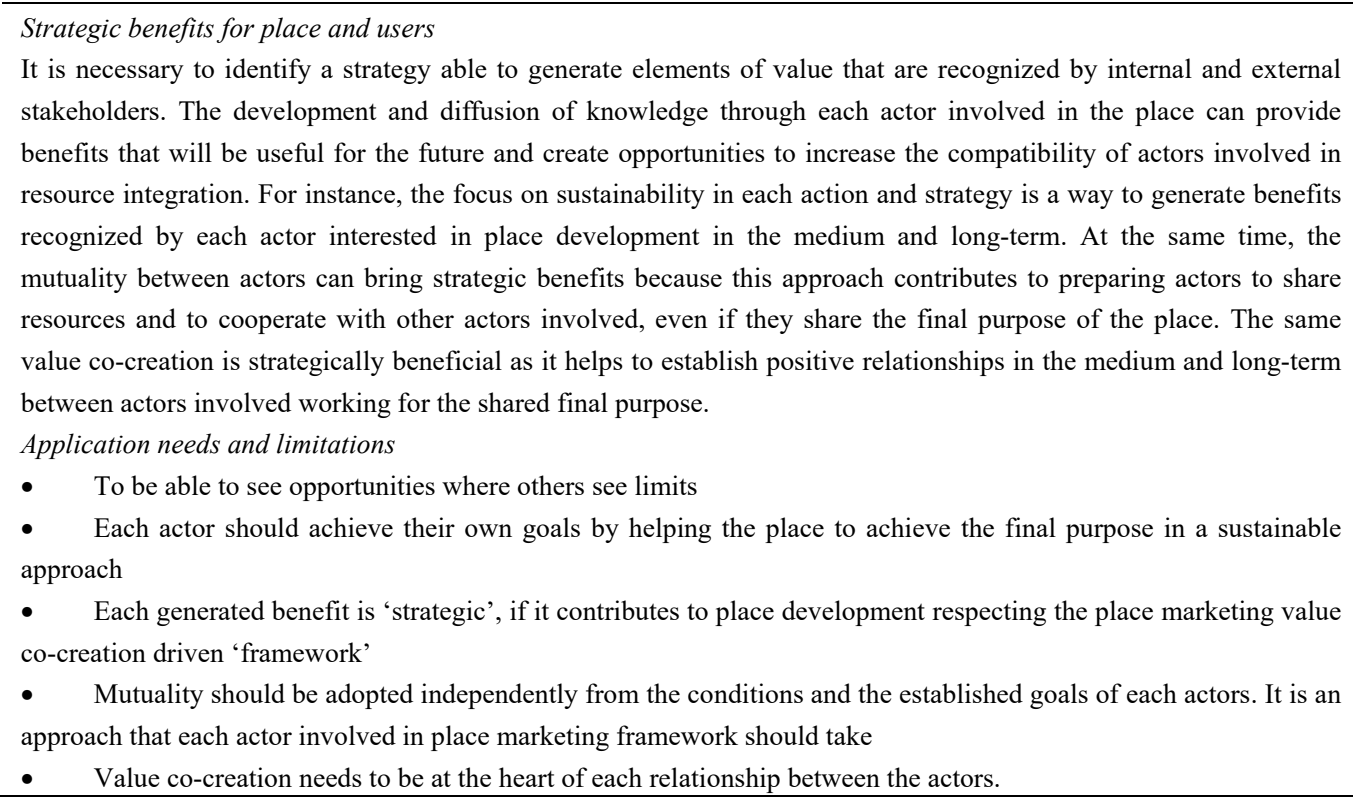

Source: authors elaboration.

It is difficult to convey the intentions and approach that each actor should have when interacting with the place in order to implement the right framework. Since the framework implies the involvement of a multiplicity of actors, it is not important what the actors should do in their core activities but, in another way, how the actors work to trasform theory into practice, particularly, management the activities in the medium and long-term and interaction with others and co-creating value for the place.

The place marketing framework focuses on actors resources integration, and for this reason the role of the network is relevant to realize the place value proposition. Value arises from the interaction between internal and external stakeholders, respecting the sustainability of the place and its final purpose, especially in terms of creating benefits for residents and internal stakeholders. In particular, local knowledge management takes on a relevant role because it generates and manages innovation, by understanding and regulating the resource sharing and integration. Further, the knowledge improvement and management permits to increase the quality of perception of value and competencies of the populations and different actors involved to design and implement a medium long-term strategy aimed at ensuring well-being and a better quality of life.

\section{Conclusions}

The interconnection, the development of networks and the dependence between economic systems have created a high level of complexity in markets, and companies have organized themselves to manage relationships with internal and external stakeholders by developing new marketing frameworks capable of going beyond communication and value proposition. As stated earlier, marketing based on value co-creation seems to generate good results in managing complexity. It is difficult to find a government that applies place marketing value co-creation driven completely because this framework implies the need to manage a high level of relationships between the actors involved. This framework is based on a shared purpose of the involved actors, focusing on well-being and quality of life, but it is not always easy to get a clear vision of each actor involved in a place. The advantages of applying this framework for government include the place collaboration, shared and sustainable 
projects and strategic benefits for place and users. Each actor will share the opportunities to be part of the territory/place value proposition and, eventually, the same actor will be available to make sacrifices at certain points, thinking about a larger and relevant goal, final purpose, that is, the territory/place survival striving for well-being and a better quality of life of people.

In order to overcome complexity and turbulence, it is possible to recommend to governments to be clear about their status and role because they are an expression of the people's will. In any case, since they have to manage relationships and place development, they should work on setting rules, codes and languages to involve actors in cooperation and ideas sharing. In this sense not, only laws are considered, but the whole system of opportunities for cooperation and exchange of projects and ideas between internal and external stakeholders. This pathway is useful for stimulating the interaction of actors and encouraging them to contribute to place development through the participation in projects design for the whole community, spreading a sense of mutuality between actors involved. The actors interaction should be stimulated and guided by mutuality and respect for the place final purpose; for this reason, it is relevant to the engagement of all actors involved. The limits can be defined in the complexity of spreading the logic of value co-creation in a place where the knowledge is not spread properly and the innovation is not positively accepted. Further, cultural and social approaches can significantly reduce the effects caused by the application of the framework, and it is necessary to manage a horizontal approach to reduce the number of rules and constraints but, at the same time, increase the level and quality of control over the interaction process.

Following these frameworks, limits and opportunities are shared between actors involved in place and government mainly takes on the role of 'movie director' encouraging actors to expand their knowledge and become involved in the final purpose of the place. Top-down and bottom-up logics in government lose their role because the value co-creation approach encourages each actor in the place to interact and participate working for their own goals, but sharing the main final purpose of the place established within the place marketing strategy. Place marketing value co-creation driven is the advanced marketing framework that transforms the government into a facilitator capable of managing the contributions coming from the system of actors involved in the place in order to stimulate the place development respecting the shared final purpose and the nature and role of each actor involved, during the time with a sustainable logic.

A limit of this work is on the approach, actually theoretical, without examples and case studies and for this reason, further studies about measuring the effects of place marketing value co-creation driven on place government activities could contribute to confirm or revise the presented approach.

\section{References}

Anholt, S. (2008). Place branding: Is it marketing or isn't it? Place Branding and Public Diplomacy, 4, 1-6. https://doi.org/10.1057/palgrave.pb.6000088

Ashworth, G. (2016). Place marketing: marketing in the planning and management of places. Routledge.

Ashworth, G. J., \& Voogt, H. (1990). Selling the city. London.

Ave, G. (1994). Urban Planning and Strategic Urban Marketing in Europe. Urban marketing in Europe, 1, 126-159. Torino Incontra.

Badinelli, R., Barile, S., Ng, I., Polese, F., Saviano, M. \& Di Nauta, P. (2012). Viable service systems and decision making in service management. Journal of Service Management, 23(4), 498-526. https://doi.org/10.1108/09564231211260396

Barad, K. (2003). Posthumanist performativity: Toward an understanding of how matter comes to matter. Journal of women in culture and society, 28(3), 801-831. https://doi.org/10.1086/345321

Berger, P. L., \& Luckmann, T. (1967). The social construction of reality. London, Allen Lane.

Borchert, J. G. (1994). Urban marketing: a review. In: Braun, G. O. (Ed.), Managing marketing of urban development and urban life. Berlin: Deitrich Reimer Verlag.

Bruni, R. (2014). Dinamiche impresa-contesto-cliente e retail di prossimità. Collana Economia e gestione delle imprese, Aracne Editrice S.r.l., Roma.

Bruni, R., \& Caboni, F. (2017). Place as Value Proposition: The Marketing Perspective. Franco Angeli. https://doi.org/10.3280/MC2017-003005

Bruni, R., \& Matarazzo, M. (2017). Figure of Merit for places: Perspectives on place branding. Mercati \& Competitività. 
Caragliu, A., Del Bo, C., \& Nijkamp, P. (2013). 10 Smart cities in Europe. In Smart cities: governing, modelling and analysing the transition (p. 173). Routledge.

Casey, E. S. (1997). Smooth spaces and rough-edged places: The hidden history of place. The Review of Metaphysics, 51(2), 267-296.

Cresswell, T., \& Hoskins, G. (2008). Place, Persistence, and Practice: Evaluating Historical Significance at Angel Island, San Francisco, and Maxwell Street, Chicago. Annals of the Association of American Geographers, 98(2), 392-413. https://doi.org/10.1080/00045600701879409

Davenport, T. H. (2014). How strategists use "big data" to support internal business decisions, discovery and production. Strategy \& Leadership. https://doi.org/10.1108/SL-05-2014-0034

de Camargo Fiorini, P., Seles, B. M. R. P., Jabbour, C. J. C., Mariano, E. B., \& de Sousa Jabbour, A. B. L. (2018) Management theory and big data literature: From a review to a research agenda. International Journal of Information Management, 43, 112-129. https://doi.org/10.1016/j.ijinfomgt.2018.07.005

Erl, T., Khattak, W., \& Buhler, P. (2016). Big data fundamentals: concepts, drivers \& techniques. Prentice Hall Press.

Florek, M., \& Insch, A. (2020). Learning to co-create the city brand experience. Journal of International Studies, 13(2). https://doi.org/10.14254/2071-8330.2020/13-2/12

Galvagno, M., \& Dalli, D. (2014). Theory of value co-creation: a systematic literature review. Managing Service Quality, 24(6), 643-683. https://doi.org/10.1108/MSQ-09-2013-0187

Giddens, A. (1984), The constitution of society: Outline of the theory of structuration. University of California Press.

Glover, T. D., \& Parry, D. C. (2009). A third place in the everyday lives of people living with cancer: Functions of Gilda's Club of Greater Toronto. Health \& place, 15(1), 97-106. https://doi.org/10.1016/j.healthplace.2008.02.007

Goes, P. B. (2014). Big data and IS research. MIS Quarterly, 38, 3-8.

Goldstone, J. A., Bates, R. H., Epstein, D. L., Gurr, T. R., Lustik, M. B., Marshall, M. G., ... \& Woodward, M. (2010). A global model for forecasting political instability. American Journal of Political Science, 54(1), 190-208. https://doi.org/10.1111/j.1540-5907.2009.00426.x

Govers, R., \& Go, F. (2009). Place branding-glocal, physical and virtual identities constructed, imagined or experienced. Palgrave Macmillan. https://doi.org/10.1007/978-0-230-24702-4

Graham, S. (1998). The end of geography or the explosion of place? Conceptualizing space, place and information technology. Progress in human geography, 22(2), 165-185. https://doi.org/10.1191/030913298671334137

Greenspan, A. (2007). The age of turbulence. New York: Penguin Press.

Gummesson, E. (2004). From one-to-one to many-to-many marketing. In Edvardsson, B., Gustafsson, A., Brown, S., Johnston, R. (Eds.), Service Excellence in Management: Interdisciplinary Contributions, Proceedings from the QUIS 9 Symposium. (pp. 16-25). Karlstad University, Karlstad.

Gummesson, E. (2008). Quality, service-dominant logic and many-to-many marketing. The TQM Journal, 20(2), 43-153. https://doi.org/10.1108/17542730810857372

Gummesson, E., \& Polese, F. (2009). B2B is not an island! Journal of Business \& Industrial Marketing, 24(5/6), 337-350. https://doi.org/10.1108/08858620910966228

Håkansson, H., \& Snehota, I. (1995). Developing Relationships in Business Network. Routledge, London.

Hermann, M., Pentek, T., \& Otto, B. (2016). Design principles for industrie 4.0 scenarios. System Sciences (HICSS), 2016 49th Hawaii International Conference on, 3928-3937, IEEE. https://doi.org/10.1109/HICSS.2016.488

Insch, A., \& Florek, M. (2008). A great place to live, work and play: Conceptualising place satisfaction in the case of a city's residents. Journal of place management and development, 1(2), 138-149. https://doi.org/10.1108/17538330810889970

Jāhāna, S. (2016). Human development report 2016: human development for everyone. United Nations Publications. 
Kotler, P. (2009). Marketing management. Pearson education.

Kotler, P., \& Kotler, M. (2014). Winning Global Markets: How Businesses Invest and Prosper in the World's High-growth Cities. John Wiley \& Sons.

Kotler, P., Haider, D. H., \& Rein, I. (1993). Marketing places. New York: Free Press.

Le Moigne, J. L. (1985). Progettazione della complessità e complessità della progettazione. In: Bocchi, G., Ceruti, M. (Eds.), La sfida della complessità. Feltrinelli, Milano.

Leitão, A. (2016). Corruption and the Environment. Journal of Socioeconomics, 5(3). https://doi.org/10.4172/2167-0358.1000173

Lusch, R. F., \& Laczniak, G. R. (1989). Macro-environmental forces, marketing strategy and business performance: A futures research approach. Journal of the Academy of Marketing Science, 17(4), 283-295. https://doi.org/10.1007/BF02726639

Maglio, P. P., \& Spohrer, J. (2008). Fundamentals of service science. Journal of the Academy of Marketing Science, 36(1), 18-20. https://doi.org/10.1007/s11747-007-0058-9

Malpas, J. (2008). Heidegger's topology: being, place, world. MIT press.

Mele, C., \& Polese, F. (2011). Key dimensions of service systems in value-creating networks. The science of service systems, 37-59. https://doi.org/10.1007/978-1-4419-8270-4_3

Musterd, S., \& Murie, A. (2010). Making competitive cities. Wiley-Blackwell, Chichester.

Oakes, S., \& Warnaby, G. (2011). Conceptualizing the management and consumption of live music in urban space. Marketing Theory, 11(4), 405-418. https://doi.org/10.1177/1470593111418798

Parker, C. (2008). Extended editorial: place-the trinal frontier. Journal of Place management and Development, 1(1), 5-14. https://doi.org/10.1108/17538330810865309

Polese, F. (2009). Local government and networking trends supporting sustainable tourism: some empirical evidences. Cultural Tourism and Sustainable Local Development, 131-148.

Polese, F., Carrubbo, L., Bruni, R., \& Maione, G., (2017). The viable system perspective of actors in eco-systems. The TQM Journal, 29(6), 783-799. https://doi.org/10.1111/j.1467-8306.1984.tb01453.x

Pred, A. (1984). Place as historically contingent process: Structuration and the time-geography of becoming places. Annals of the association of American geographers, 74(2), 279-297.

Ramaswamy, V., \& Ozcan, K. (2018). What is co-creation? An interactional creation framework and its implications for value creation. Journal of Business Research, 84, 196-205. https://doi.org/10.1016/j.jbusres.2017.11.027

Ranjan, K. R., \& Read, S. (2016). Value co-creation: concept and measurement. Journal of the Academy of Marketing Science, 44(3), 290-315. https://doi.org/10.1007/s11747-014-0397-2

Rosenbaum, M. S. (2006). Exploring the social supportive role of third places in consumers lives. Journal of Service Research, 9(1), 59-72. https://doi.org/10.1177/1094670506289530

Sansone, M. (2012). Place management: città territori marketing. Milano: McGraw-Hill.

Seamon, D. (2013). Lived bodies, place, and phenomenology: Implications for human rights and environmental justice. Journal of Human Rights and the Environment, 4(2), 143-166. https://doi.org/10.4337/jhre.2013.02.02

Teece, D. J. (2014). A dynamic capabilities-based entrepreneurial theory of the multinational enterprise. Journal of International Business Studies, 45(1), 8-37. https://doi.org/10.1057/jibs.2013.54

Teece, D., \& Pisano, G. (1994). The dynamic capabilities of firms: an introduction. Industrial and corporate change, 3(3), 537-556. https://doi.org/10.1093/icc/3.3.537-a

Townsend, A. M. (2013). Smart cities: Big data, civic hackers, and the quest for a new utopia. WW Norton \& Company.

United Nations. (2020). Department of Economic and Social Affairs World-economic-situation-and-prospects-2020 Retrieved from https://www.un.org/development/desa/dpad/publication/world-economic-situation-and-prospects-2020/

Van den Berg, L., Bramezza, I., \& Van der Meer, J. (1994). Gestione e marketing della città: l'esperienza 
olandese. Impresa e Stato. 27.

Vargo, S. L., \& Lusch, R. F. (2004). Evolving to a new dominant logic for marketing. Journal of Marketing, 68, 1-17. https://doi.org/10.1509/jmkg.68.1.1.24036

Vargo, S. L., \& Lusch, R. F. (2016). Institutions and axioms: an extension and update of service-dominant logic. Journal of the Academy of Marketing Science, 44(1), 5-23. https://doi.org/10.1007/s11747-015-0456-3

Ziadat, F., Bunning, S., \& De Pauw, E. (2017). Land resource planning for sustainable land management. FAO. Retrieved from http://www.fao.org/3/a-i5937e.pdf

\section{Copyrights}

Copyright for this article is retained by the author(s), with first publication rights granted to the journal.

This is an open-access article distributed under the terms and conditions of the Creative Commons Attribution license (http://creativecommons.org/licenses/by/4.0/). 